\title{
Knowledge exchange partnership leads to digital transformation at Hydro-X Water Treatment, Ltd.
}

\section{DRAFT PUBLICATION 28/2/18}

\begin{abstract}
Aleksej Heinze | Marie Griffiths | Alex Fenton | Gordon Fletcher
Guided by university researchers and a pair of theoretical business models, the managers of a British firm improved its e-commerce platform to attract tech-savvy customers while developing a new stream of revenue.
\end{abstract}

To attract a generation of workers and consumers who have never known a world without Wi-Fi, smartphones, or social media, organizations increasingly have no choice but to incorporate digital technology into every aspect of their operations and processes. The leaders of Hydro-X, a privately owned British enterprise, met the challenge of digital transformation by forming a knowledge exchange partnership with a local university and applying two business models to assess the current state of digital maturity at the firm and map out a strategy to improve it. Their experiences reflect the HINGE project planning methodology: Horizon scanning to evaluate the competition, Internal auditing, New model creation, Gap analysis, and Evaluation of options to determine next steps. As a result of their efforts, Hydro-X fostered an intrapreneurial spirit among its staff and refined its e-commerce platform to digitally target key audiences in order to tap into a new source of revenue.

Digital transformation is both a challenge and an opportunity. To date, most organizations have used digital technology in a tactical sense: to bring immediate, short-term, benefits in key functional areas. Digital technology, however, can be deployed much more broadly to 
strategically change an organization's operations, processes, and functions. In short, a successful digital transformation results in a data-driven enterprise.

Although the benefits of digital transformation can be significant (Provost \& Fawcett, 2013), few organizations have been able to make the far-reaching, systematic changes needed to transform an existing organization into a digital business. This lack of progress is surprising at a time when technological and socio-economic change is a constant feature in both developed and developing economies. For example, an increase in the rate of internet penetration, connection speeds, and mobile device uptake means that businesses must constantly react to such changes. Similarly, customers increasingly expect to engage with rich content, such as video or images, as part of an "always on," mobile connected experience.

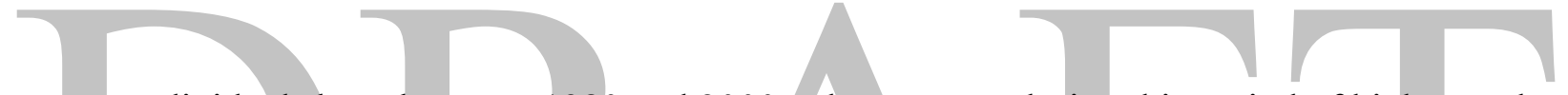

Individuals born between 1980 and 2000, who grew up during this period of high-speed digital change, have begun working and are predicted to form half the global workforce within the next ten years (Faour \& Heinze, 2013). Most of these people have never known a “disconnected" world without Wi-Fi, smartphones, tablets, or social media. They are simply accustomed to digital technology and expect to use it in their daily work. This new generation of employees, sometimes termed millennials or digital natives, is unfamiliar with non-digital business technologies, such as telex and fax, or paper-based resources like the Yellow Pages, which were a mainstay of business communications. Today's workers — and customers — rely on mobile devices and services, such as search engines or social media, to find the information they need.

Given this generational change, organizations that wish to succeed must digitally transform, and they must be open to the innovation needed to drive this change. Such a daunting 
task may require drastic changes in existing business process, business models, products, or services. Ideally, the new generation of employees will be able to spark these innovations through intrapreneurial actions — that is, by acting as internal entrepreneurs to combine technology, data, and systems to produce the new elements of a successful digital transformation.

Once an organization's leaders have acknowledged the need for digital transformation, they must decide how and where to start. At Hydro-X Water Treatment, Ltd., a water treatment plant in Dinnington, England, the answer was found through a knowledge exchange partnership with the University of Salford's Business School, which had relevant practical expertise in digital business research and consultancy.

\section{[H1] CHANGE IS THE ONLY CONSTANT}

In mechanical systems, deterioration occurs due to wear and tear and is corrected by the repair or replacement of a component. Software, however, continues to function in precisely the same way until it is changed. Software is changed when people decide its current behavior is in some way wrong or inappropriate. Since change is intrinsic to human behavior, changes to software are inevitable (Vasconcelos, Kimble, Carreteiro \& Rocha, 2017). Such changes not only require new code, but also may require users to adjust the way they interact with the software.

Change driven by software is especially evident in such areas as cloud-based computing and social media, where organizations no longer have control over upgrades and updates are applied remotely and automatically. For example, until late 2017 Twitter limited the number of characters in a message to 140 ; now the limit is 280 . Organizations that used the platform had to learn how to use this additional capacity in ways that would be meaningful for their customers. 
Similar changes can be seen in other innovations introduced by third-party companies, such as live video streaming, user tagging, scheduling, and analytics, all of which require tests and investigations to see how these features can best be used. This need for research and experimentation emphasizes the importance of a supportive organizational culture and a management that is prepared to take risks and tolerate failure during technology-enabled business transformations (Kumar Basu, 2015).

\section{[H2] New organizations, new business practices}

The impact of digital transformation can be seen in changes in business practices, and is most obvious in digital-sector organizations, such as software developers. For example, issues of organizational transparency are being championed by organizations such as the social media management platform Buffer, where the salaries of all employees are shared openly (Gascoigne, 2016). This approach contrasts with the opaqueness of senior management salaries in traditional organizations such as UK universities where, recently, freedom of information requests were needed to find out how much vice-chancellors were paid (The Guardian, 2017).

In some organizations, changes come in the form of geographical structure. For example, the marketing agency 90 Digital has no physical office and its employees can work anywhere in the world (90 Digital, n.d.). The flexibility needed for this type of virtual working arrangement is achieved with online conferencing and communications tools, such as Skype, Google Hangouts, Google Docs, Breeze, and Slack, as well as email.

Other organizations such as Crisp, a management consultancy business, have seen changes in practices and organizational structure. Crisp's employees are empowered to act without line managers or a CEO (Crisp, n.d.). Similarly, organizations such as Atlassian give 
their employees the freedom to master what they like doing (Atlassian, n.d.). This concept of "mastery in what we do" is considered to be a crucial motivator for employees in the knowledge economy and the digital sector (Pink, 2012).

\section{[H2] Intrapreneurship and knowledge}

This personal, individual aspect of digital transformation is one reason why intrapreneurship is viewed as an attribute for organizations that wish to transform their organizations. Intrapreneurs are seen as central to the ongoing success of a digital organization and the focal point for innovation. These employees deliver the energy required for constant evolution and provide the agility that allows their organization to develop further (Chakhoyan, 2017).

\footnotetext{
To achieve self-driven, internal innovation, many of the most successful large businesses within the digital and knowledge economies have resorted to acquiring smaller businesses to stimulate intrapreneurial actions. Google acquired YouTube, Microsoft acquired Skype, and Facebook purchased WhatsApp partly to keep up with market needs, but also to inject a new spirit of aspirational transformation into their existing organization. This approach of bringing new knowledge into an existing organization is well documented (Pangarkar, 2018) and resonates with the Hydro-X's experience.
}

\section{[H1] TWO MODELS FOR DIGITAL TRANSFORMATION}

Organizations in the digital sector need to have a clear, strongly defined business model that ensures the sustainability of digital transformation by developing and utilizing internal capabilities. The business model canvas (see Exhibit 1), a collaborative, crowd-sourced project using input from 470 strategy practitioners, provides a tool to help build such a model 
(Osterwalder \& Pigneur, 2010). It consists of nine distinct but interconnected aspects of an organization's structure and activities arranged in two layers. The seven boxes in the upper layer relate to identifying and delivering value to customers, while the lower two boxes concern the financial impact. The business model canvas enables users to reflect on current business models and design new ones. Because it offers a structured view of an organization, it is also an effective complement to such traditional tools as PESTLE (political, economic, social, technological, legal, and environmental) and SWOT (strengths, weaknesses, opportunities, and threats) analysis.

\section{EXHIBIT 1 The business model canvas}

The Business Model Canvas
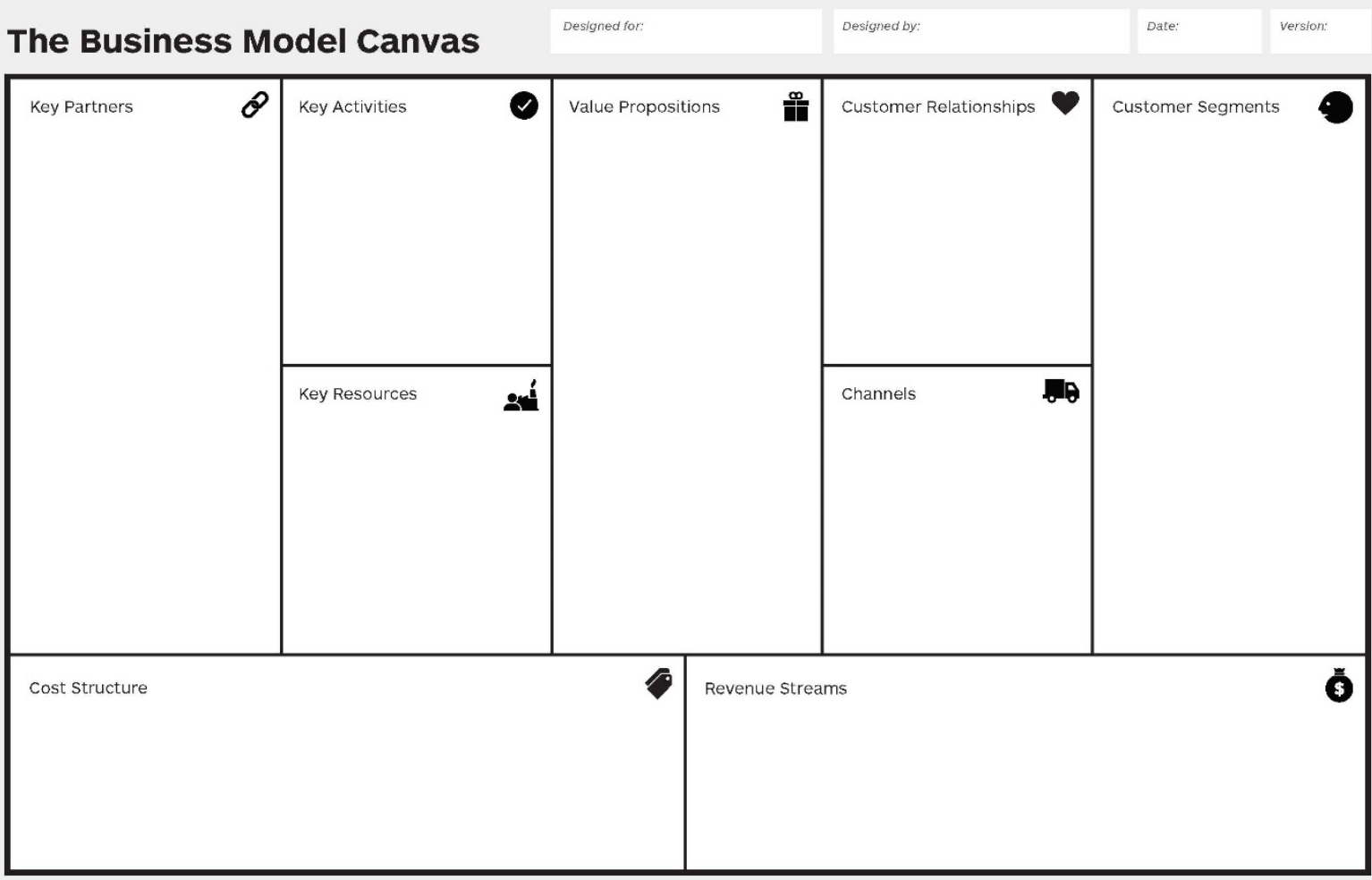

(구)(1)

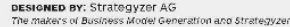

(S)Strategyzer

strategyzer.com

Reproduced under creative commons Attribution-Share Alike 3.0 Unported License: http://creativecommons.org/licenses/by-sa/3.0/. 
Users of the business model canvas begin by defining value propositions. Since these propositions are central to the business model canvas, they are positioned in the middle of the model. Subsequent elements of the canvas extend from these focal statements. These are clear statements of the benefits that their organization offers to its customers - the ways in which a customer can gain value from interacting with the organization. There is no need to specify whether value is delivered through products or services. Since digital transformation means that all business functions are delivered via digital, data-driven processes, the value propositions offered to customers will almost certainly be data-oriented.

Once value propositions have been identified, it is possible to identify the primary customer segments. These are the types of customer who are most likely to engage with the value

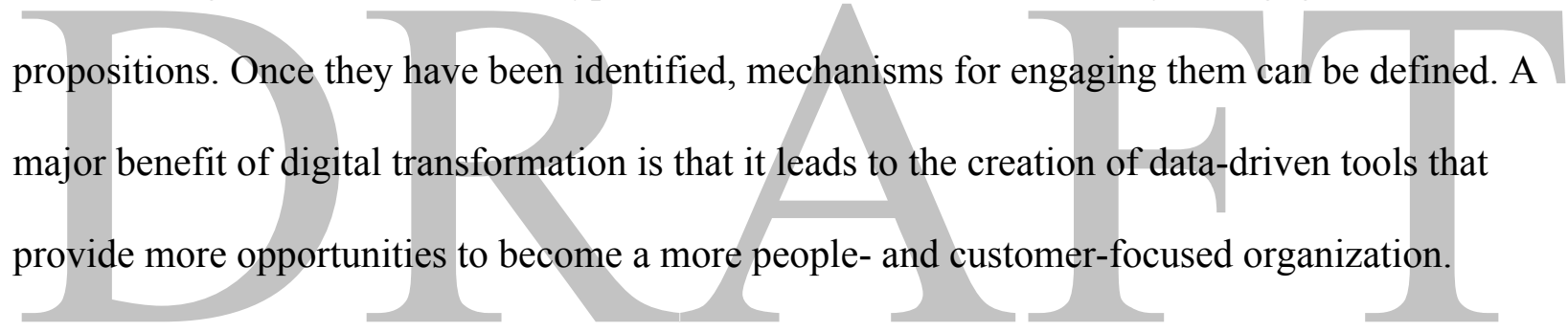

The customer segments are reached through a range of customer relationships and channels. During digital transformation, a digital-first approach will guide the specific definition of these channels toward, for example, social media, with the more traditional, non-digital, channels being defined after the more preferred digital routes have been identified.

The activities section of the business model canvas shows the ways in which the value propositions are conveyed and supplied to customers through their preferred channels. In cases of digital transformation, these activities generate data for the organization and enable an ongoing cycle of improvement and engagement. These activities allow the business to engage with 
customers, which is made possible through a fully digital workflow that includes tools for continuous monitoring and reporting.

The resources portion of the business model canvas helps to identify the assets that enable the business model to be sustainable over time, including its systems and people. Digital transformation presents significant challenges, for it requires the creation of new roles and working relationships that may challenge existing structures and assumptions. Ensuring that these resources are supported — sometimes to the detriment of existing requirements — is a fundamental challenge for management. This does not necessarily mean that jobs will be lost, but almost certainly means that existing skills and roles will change.

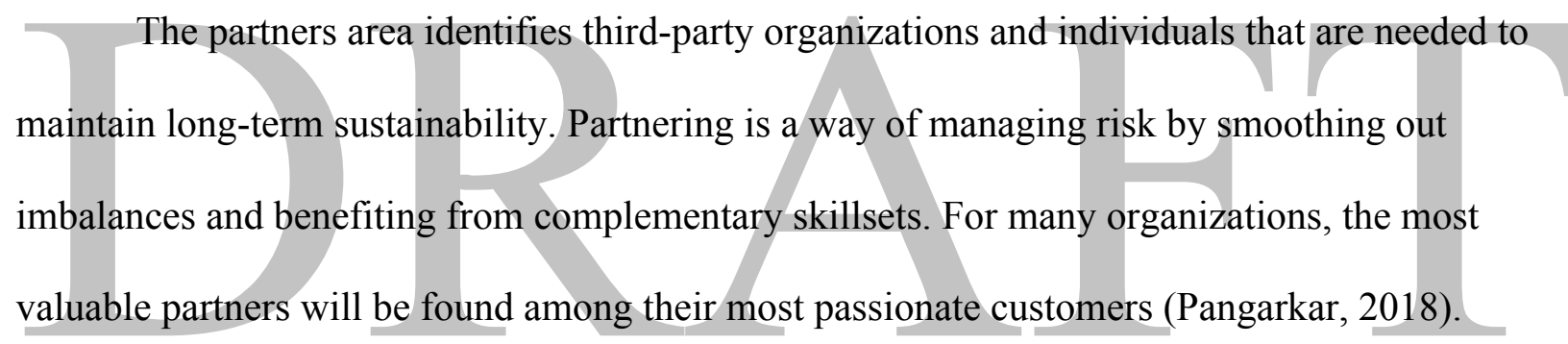

In the lower two boxes of the business model canvas, cost structure documents the expenses associated with engaging with partners, the use of channels to reach customers, acquiring the resources required, and the delivery of crucial activities. The income produced by engaging with customers is captured in the lower right revenue stream box of the canvas.

As noted earlier, the business model canvas can be used both to capture the initial current state of an organization, as well as to predict its future state as a digital business. This future state — a digital business future - represents a vision that can be used to chart an organization's future business trajectory; but this requires having a way to assess the state of a digital business's maturity. 


\section{[H1] The digital business maturity model}

The digital business maturity model (see Exhibit 2) can be used to assess digital business maturity (Heinze, Fletcher, Rashid \& Cruz, 2016). This model assumes that organizations will move toward a more mature position over time while customer expectations and competitors' maturity will also increase. The process of achieving digital maturity, therefore, can never truly be accomplished. Understanding this reality is the first challenge for an organization undertaking digital transformation.

\section{EXHIBIT 2 The digital business maturity model}

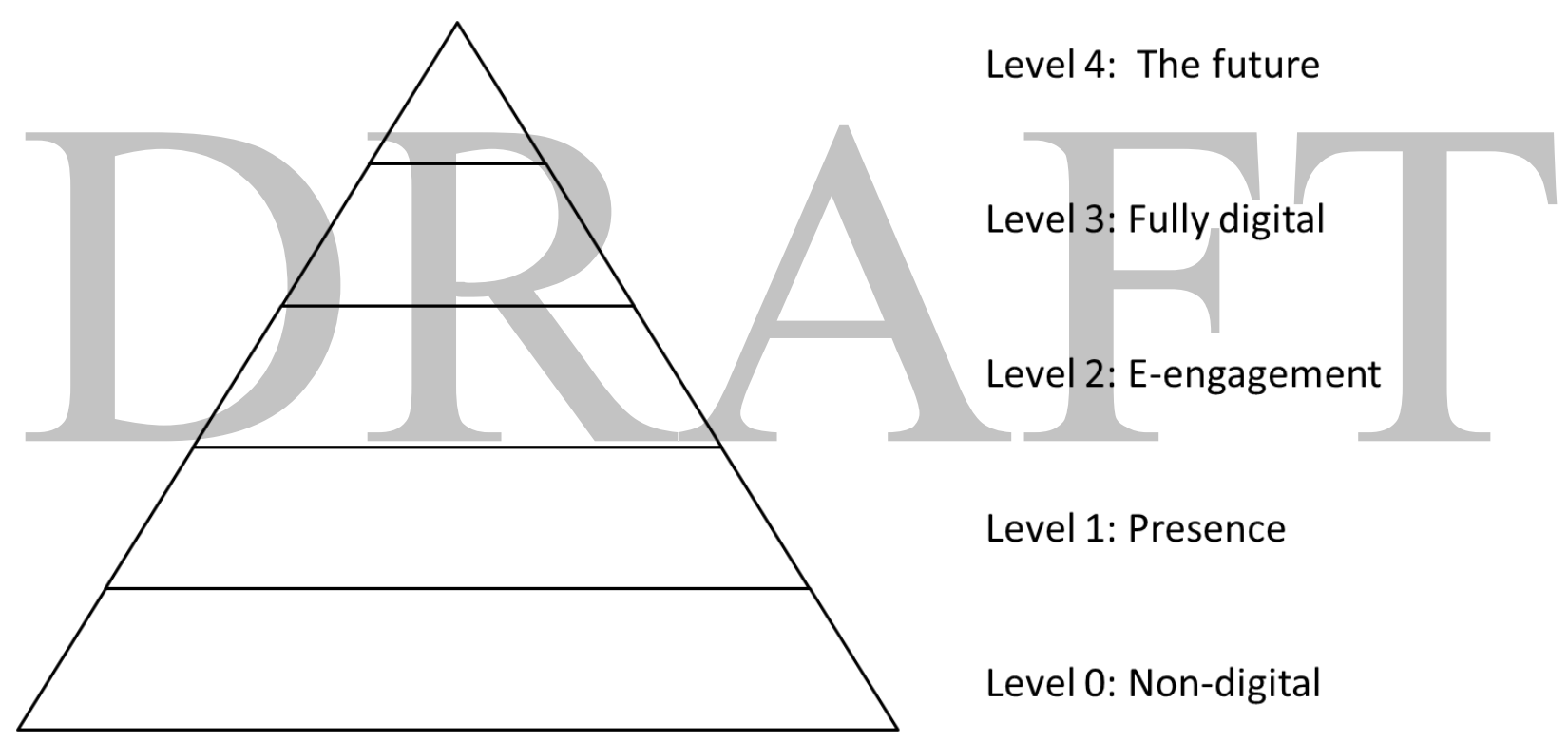

Adapted from Heinze, Fletcher, Rashid, \& Cruz, 2016.

Level 0 in the model represents organizations that are not digitally proactive. Although they may make some use of email or social media, there is no consistent organizational view concerning the use of digital technology. In many respects, this illusion of digital presence is an easy position to maintain. Organizations might have digital profiles created for them by online 
directories, such as those from Google or LinkedIn, or customers may create pages for the business. These actions, however, are undertaken by unconnected third parties, not business partners. The information that is produced is not verified by the business so, in this respect, it does not own or control its digital footprint.

At level 1, the organization is at least conscious of developments in digital business and has taken ownership of its online presence. For example, the organization may have a Facebook page, a website, or a customer database. These activities tend to focus on marketing and may not have any connection to the overall business. There is no recognition of the need for the organization to become data-driven. Any digital and even data-driven marketing functions are viewed as broadcast activities. Messages are sent out to an undifferentiated, or barely differentiated, audience, and there is little or no ability to respond to incoming messages, other than those directly relating to sales.

Organizations at the e-engagement level take a more strategic and integrated approach to digital technologies. Online shopping functionality may be offered via external e-commerce platforms, such as Amazon or eBay, or through an internally produced website. Internal systems, such as e-human resource management systems and online collaboration tools, will be commonly used within the organization's everyday operations. Systems integration or data sharing among these various systems, however, will be, at best, irregular and inconsistently applied. The use of social media will be more interactive than it is in the lower levels of the model, with customer engagement encouraged, but the capacity to develop and sustain these activities will be limited.

At level 3, the fully digital level, an organization is wholly dependent on digital technology, and much of its decision making will rely on data gathered from its customer 
channels. At this level, digital technology drives all operations, sales, and marketing activities. Although there are currently few organizations of this type, technology-based innovators like Uber illustrate the potential. All of Uber's business processes — the distribution of its drivers, the company's pricing algorithm, and its channels of communication — rely on a fully digitized supply chain that links customers, drivers, and the company.

Other organizations at this level, such as Airbnb, eBay, and Back Market, have taken traditional face-to-face business models as their starting point and re-engineered them to produce fully digital business models. This approach removes intermediaries from complex business relationships, leading to lower cost structures that result in novel revenue streams. Atlassian, 90 Digital, Buffer, and Microsoft are also moving toward this heightened level of digital maturity, with the seamless flow of data between organizational functions being increasingly placed at the core of their business.

Representing an aspiration that is unattainable in the near term, the final level in the model offers a vision of the future. It represents a fully digital organization striving for a value proposition that will challenge an entire sector. Existing technologies like artificial intelligence, blockchain ledgers, autonomous vehicles, and always-on sensory devices offer glimpses of the type of hardware that could be at the core of future digital business models. Organizations at the forefront of digitally driven innovation include Tesla, which is defining consumer expectations for electric cars, and Virgin Galactic, which is seeking to make space travel available to anyone who can afford it. Others are working on prototypes of technologies that, though still on the cusp of widespread consumer acceptance, may shape future interactions and expectations. 


\section{[H1] THE DIGITAL TRANSFORMATION OF HYDRO-X}

Hydro-X is a privately owned, small to medium-size enterprise situated in Dinnington, on the outskirts of Sheffield, a large city in northern England, the heartland of early industrial Great Britain. Traditionally dominated by the manufacture of various items, such as high-quality steel products in Sheffield, the region now has a more diverse economy. Like many cities in the area, over the past 20 years Sheffield has seen the development of a local knowledge-based economy and a steady growth in creative and digital industries (TechNation, 2017). Sheffield's location in the center of the United Kingdom and its good transportation infrastructure have contributed to its economic regeneration, and led to the formation of a knowledge hub supported by two local universities, the University of Sheffield and Sheffield Hallam University.

\footnotetext{
Established 33 years ago, Hydro-X specializes in water treatment services. It has more than 70 staff members, links to 50 companies worldwide, and regional offices located close to main industrial areas in the United Kingdom. The firm's services cover most aspects of wastewater treatment, including Legionella detection and control products and services, boiler water treatment services, plant design, and construction equipment. Heavily regulated, the British water treatment sector is subject to standards set by central and regional governments in the United Kingdom and the European Union, as well as to global guidelines issued by the World Health Organization and other international bodies. Since there is a constant demand for training to keep up with new and existing regulations, Hydro-X has extended its product portfolio to include training in health and safety $(\mathrm{H} \& \mathrm{~S})$. The company has forward-looking senior managers who want the company to grow in capacity, become more scalable, and diversify into new markets. The management team collectively exhibits a strong experimental mindset and has embraced the idea of digital transformation.
} 
In 2015, Hydro-X launched an open source e-commerce platform to sell water treatment products, which also offered online H\&S training. This foray into online training proved profitable, so the company decided to extend its provision to capture a greater share of the H\&S training market. Having tested the market for online learning through its customized e-commerce platform, as well as via in-person courses for new and existing customers, the company decided to become an accredited education provider. To this end, its managers sought external accreditation of the firm's training courses from City and Guilds, a UK-based organization that specializes in setting standards for vocational education and industrial apprenticeships.

\section{[H2] Seeking outside assistance}

To further their plans, the management team decided to form a Knowledge Exchange Partnership (KXP) with Salford Business School, part of the University of Salford located in Greater Manchester. The school would contribute various resources, such as an academic team with expertise in digital transformation, and recruit a full-time employee for the project, known as a knowledge exchange associate. This associate works for the university on a fixed term contract, but is based at Hydro-X and leads the KXP project there. The goal of the KXP was to develop the functionality of Hydro-X's customized e-commerce platform and assist with the company's digital transformation.

The academic team members decided to take an action case approach (Braa \& Vidgen, 1999) in which ideas are tested in the client organization and a researcher intervenes to bring about a desirable change. The aims were to improve the company's existing situation and competitive advantage. The academic team members familiarized themselves with Hydro-X's operations and worked closely with the company to facilitate change through a series of 
interventions. One of the goals was to develop an organizational spirit of intrapreneurship that would lead to a successful digital transformation.

The KXP involves weekly meetings between the associate and the academic team from Salford Business School; monthly meetings attended by the company’s management team, the academic knowledge base team, and the associate; and quarterly meetings of company managers, the academic knowledge base team, the associate, and the KXP funds management team, which was established to ensure compliance with Higher Education Innovation Fund (HEIF) regulations regarding university partnerships with industry. The weekly and monthly meetings focus on operational issues; the quarterly meetings address the strategic direction of the project.

\footnotetext{
As of this writing, the project has resulted in the implementation of an improved version of the company's e-commerce platform that will contribute to further digital transformation and a new business model. Future plans call for integrating more automated processes into the organization to improve the accuracy of tracking learners' progress and their ability to interact with the online training system beyond the lifetime of a course, and integrating daily jobs through a system dashboard that can be used for managing and monitoring day-to-day work at Hydro-X. These improvements are expected to increase the likelihood that clients will use the online training system for more than just one H\&S course.
}

\section{[H1] LESSONS FROM HYDRO-X}

Most of the data presented here was collected during the first year of the KXP at HydroX. A combination of data sources was necessary to further the understanding of the challenges that the company faced. Researchers and company staff members collected quantitative data from in-house financial statistics, website interaction data from Google Analytics, online sales data, 
and an online customer survey. They gathered qualitative data by observing and participating in meetings with the company's executive team. They also conducted follow-up telephone interviews as part of the online customer survey.

In terms of the digital business maturity model, Hydro-X was initially situated between levels 1 and 2. Although e-commerce could be conducted on the company's website, it was mainly used for sales and broadcast communications. The company's progressive senior management team, however, sought to modify the existing open-source e-commerce platform in order to exploit new opportunities in H\&S training and further the digital transformation of the business. Their experience highlights several lessons.

\footnotetext{
Use effective models. The holistic approach of the business model canvas allows for a thorough consideration and assessment of the impact of reaching a new level of digital maturity. Managers at Hydro-X used the business model canvas to document existing and future situations. This enabled them to identify the aspects of the digital business model that required attention for their initial plans, which helped them clarify the challenge they were addressing and improve the transparency of communications across the team. A customer survey and follow-up interviews were used to refine the value propositions for different market segments, and to reprioritize the cost and revenue structures.
}

These actions also assisted management in making comparisons within the team and with external stakeholders. For example, the survey asked about the perceived value of accredited learning to the target audience, and the results helped clarify priorities and define the strategic partners within the Hydro-X's business model. Since training was identified as an important method for disseminating the skills and knowledge required for digital transformation, the 
knowledge exchange associate was trained in search and social media marketing techniques, and then shared this knowledge with his colleagues. The additional benefit of this tactic was to increase buy-in to the project among other team members.

Partnerships can be valuable. The KXP was used to develop a new digital learning platform and brought a new set of capabilities that allowed the organization to market its products and services and transact business online. The formal collaboration between the organization and the university provided a systematic route for measured and sustainable knowledge transfer. The researchers were all experienced academics who specialized in knowledge transfer and had contributed to a range of digital transformation processes in other organizations. They brought technical and organizational theory into the transformation process and were able to connect the company to other experts when required. In line with the business model canvas, the university and the KXP associate acted as key partners and helped Hydro-X to reach a new level of digital maturity.

Levels of maturity can differ among activities. Fully reaching a particular level in the digital business maturity model is only possible when all aspects of digital interaction have attained the same level. The Hydro-X experience, however, showed that different levels of maturity could be found in different parts of the business. The company had social media profiles, an extensive mailing list that was used to regularly send out newsletters and to notify sales prospects about new courses, and an automated e-commerce function on its website, all of which suggest an e-engagement level of maturity (level 2). Other activities within the organization, including the passive use of social media and a reliance on Google AdWords-based advertising, however, indicated a lower level of digital maturity. 
Management commitment is essential. Hydro-X's leaders were inspired to attain the third level of digital business maturity: e-engagement. They realized that allowing learners to interact online would enable the delivery of online learning to drive the growth of the training part of the company's business. Numerous training-related products were developed that could be offered through the new customized e-commerce platform, along with several additional digital services that went beyond the scope of other competing training providers. To find out which products and services were best suited to their customers' needs, managers had to be prepared to experiment, take risks, and put up with the occasional failure.

\section{[H1] THE HINGE CYCLE OF DIGITAL TRANSFORMATION}

The experiences of Hydro- $\mathrm{X}$ and other organizations grappling with digital transformation show that project planning for digital transformation tends to follow a five-stage HINGE cycle: Horizon scanning, Internal auditing, New model creation, Gap analysis, and Evaluation of options (see Exhibit 3). This cycle enables organizational leaders to construct a systematic project plan that enables their enterprise to reach new levels of digital maturity, while documenting their existing business model in a holistic and meaningful way. This is how the HINGE cycle was manifested at Hydro-X:

- $\quad$ Horizon scanning: Evaluating the external environment. At this stage the researchers and Hydro-X worked together to assess alternative technologies and online training methods used by other H\&S training providers. New delivery technologies, such as mobile and video, were noted as potentially important components of any future online training system. Technological developments in other fields beyond H\&S training, such as massive open online courses (MOOCs), were also assessed. 
- Internal audit: Assessing the internal environment. The technical skills and technological infrastructure of Hydro-X were evaluated. Meetings with main stakeholders took place and their views about the existing infrastructure and staff skills were considered.

- $\quad$ New models: Reaching new business maturity levels and creating new business models. New digital maturity levels and business models were explored and relevant aspects of change were identified. A business model canvas for the existing and future state of the transformation was drafted.

- Gap analysis: Evaluating current and future states of the business. The gap between current and future digital business maturity stages and business models were identified, and plans were made to bridge those gaps. Technical requirements were identified and listed, and the capabilities of the current digital systems and processes were assessed.

- Evaluation of options: Testing and evaluating. The feasibility of the various options was assessed against the priorities that were identified, and the related costs and benefits of each were highlighted. This information was reviewed during weekly, monthly, and quarterly meetings and acted upon as appropriate.

\section{EXHIBIT 3 The HINGE pattern of digital transformation project planning}




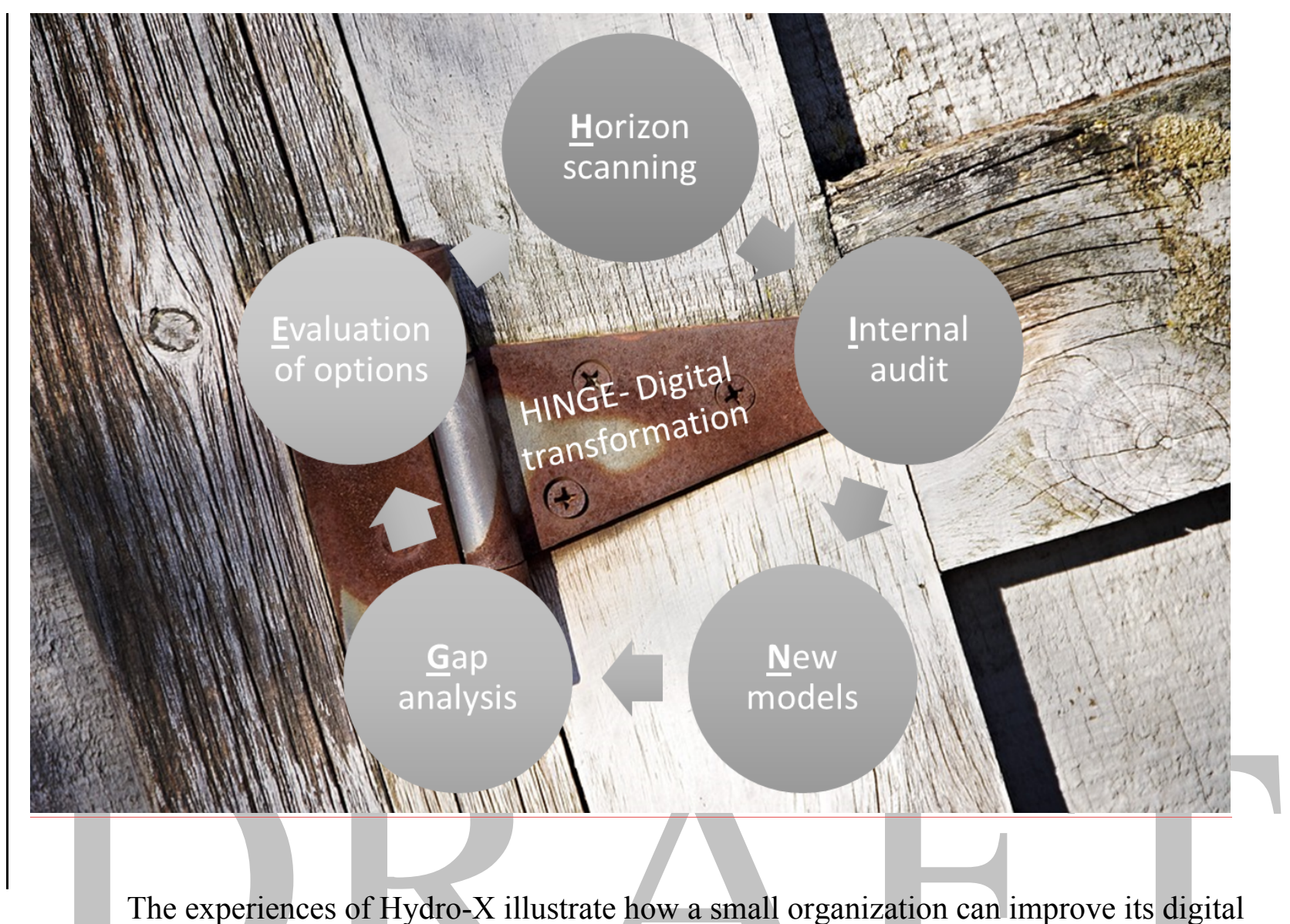

maturity by collaborating with an external change agent such as a university. The current project planning process at the company continues to lead to effective transformation and competitive advantage. Over the last 10 years, partnerships at other organizations have yielded similar benefits. The key to success in all these cases is collaboration between a company and a university facilitated by a full-time employee — the knowledge exchange associate — who has access to a range of resources that are not typically available to organizations of average size.

Developing a strategy to improve the digital maturity of an organization must take into account both internal and external perspectives. At Hydro-X, this was done via internal meetings and the application of the business model canvas and the digital business maturity model to discuss and highlight the key changes in core business functions and perspectives that were 
needed. Even though those models are theoretical tools, Hydro-X's managers showed that they can be used to re-think the digital maturity of a firm and target key audiences in increasingly sophisticated, individualized, and digitally connected ways.

Increasing internet penetration rates worldwide, coupled with millennials' expectations of digital interaction and engagement, make it essential for all organizations to become digitally mature. The tools, techniques, and ideas presented here can help business leaders navigate that challenging transformation.

\section{REFERENCES}

90 Digital. (n.d.). About 90 digital. Retrieved January 17, 2018, from https://90digital.com/about-

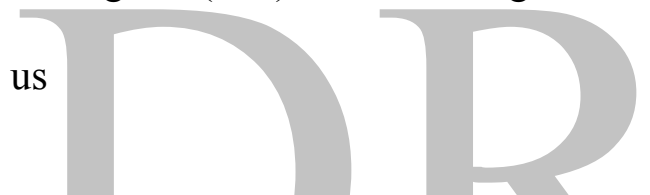

Atlassian. (n.d.). Go from dream to done, with Atlassian. Retrieved January 17, 2018, from

https://www.atlassian.com/

Braa, K., \& Vidgen, R. (1999). Interpretation, intervention, and reduction in the organizational laboratory: A framework for in-context information system research. Accounting, Management and Information Technologies, 9(1), 25-47.

Chakhoyan, A. (2017, December 7). Is the era of management over? Retrieved January 17, 2018, from https://www.weforum.org/agenda/2017/12/is-management-era-over/

Crisp. (n.d.). Crisp DNA. Retrieved January 17, 2018, from http://dna.crisp.se/docs/index.html

Faour, H., \& Heinze, A. (2013). The use of social media to attract generation Y in organisations. In UK Academy for Information Systems 18th Annual Conference. Oxford, UK: UKAIS. 
Gascoigne, J. (2016, June 1). Introducing open salaries at Buffer: Our transparent formula and all individual salaries. Retrieved January 17, 2017, from https://open.buffer.com/introducing-opensalaries-at-buffer-including-our-transparent-formula-and-all-individual-salaries/

The Guardian. (2017, November 24). Vice-chancellors' pay that is 'out of kilter' will be dealt with - regulator. Retrieved January 17, 2018, from https://www.theguardian.com/education/2017/nov/24/vice-chancellors-pay-regulator-office-forstudents-michael-barber

Heinze, A., Fletcher, G., Rashid, T., \& Cruz, A. (Eds.). (2016). Digital and social media marketing: A results-driven approach. London: Routledge.

Kumar Basu, K. (2015). The leader's role in managing change: Five cases of technology-enabled business transformation. Global Business and Organizational Excellence, 34(3), 28-42.

Osterwalder, A., \& Pigneur, Y. (2010). Business model generation: A handbook for visionaries, game changers, and challengers. Hoboken, NJ: Wiley.

Pangarkar, N. (2018). The formula for successful innovation at SAS: Integrating internal and external knowledge. Global Business and Organizational Excellence, 37(2), 24-31.

Pink, D. H. (2012). Drive: The surprising truth about what motivates us. New York: Riverhead Books.

Provost, F., \& Fawcett, T. (2013). Data science and its relationship to big data and data-driven decision making. Big Data, 1(1), 51-59. 
TechNation. (2017). Tech nation report 2017-Key findings. Retrieved January 17, 2018, from https://technation.techcityuk.com/

Vasconcelos, J. B., Kimble, C., Carreteiro, P., \& Rocha, Á. (2017). The application of knowledge management to software evolution. International Journal of Information Management, 37(1), 1499-1506.

\section{[H1] ACKNOWLEDGEMENT}

The knowledge exchange project between Hydro-X Water Treatment, Ltd., and Salford Business School was funded with support from the University of Salford Higher Education Innovation Funds (HEIF). This article reflects the views of the authors; the sponsors cannot be held responsible for any use that may be made of the information contained herein. The authors would also like to acknowledge the contributions of Paul Wilson, business systems and marketing strategies manager at Hydro-X, and Johnson Bankole, the project's knowledge exchange associate, to this article.

\section{[H1] AUTHOR BIOGRAPHY}

Aleksej Heinze, PhD, is an associate professor of digital marketing at KEDGE Business School, in Marseille, France. He received his doctoral degree at the University of Salford, and his research interests include digital marketing, with a particular focus on such key channels as search engines and social media. Dr. Heinze can be reached at aleksej.heinze@kedgebs.com.

Marie Griffiths, PhD, is a reader at Salford Business School, United Kingdom. She received her doctoral degree at the University of Salford and has a significant experience with digital research 
projects that have explored the commercial and societal implications of technological change. Dr. Griffiths can be reached at m.griffiths@salford.ac.uk.

Alex Fenton is a lecturer in digital business at Salford Business School, United Kingdom. He formerly was a manager and website developer at ED Interactive and has conducted research on the use of technology for teaching and learning, digital marketing, social media, and sport. Mr. Fenton can be reached at a.fenton@salford.ac.uk.

Gordon Fletcher, PhD, is an academic unit head at Salford Business School, United Kingdom. He received his doctoral degree at Griffith University in Australia, and his research focuses on specific examples of digital business and culture. Dr. Fletcher can be reached at g.fletcher@salford.ac.uk.

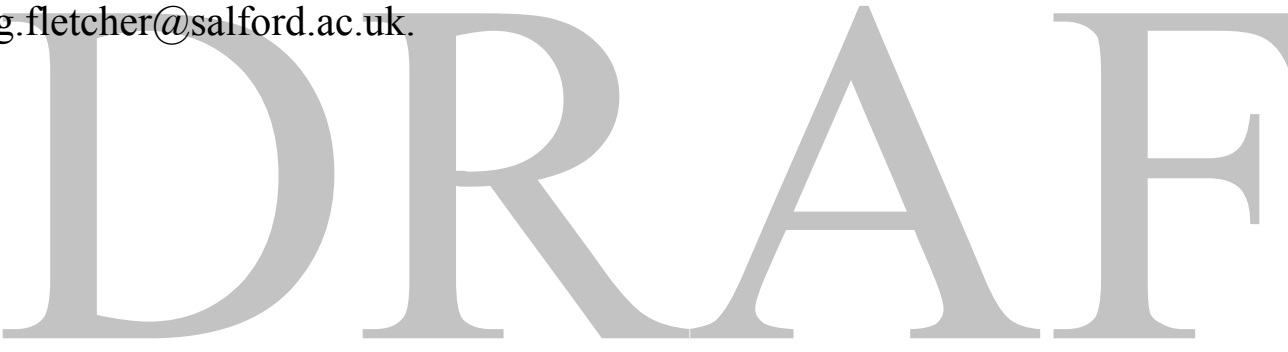

